\title{
Efeito de sistemas de preparo do solo e métodos de irrigação sobre a cultura do caupi em várzeas em Roraima
}

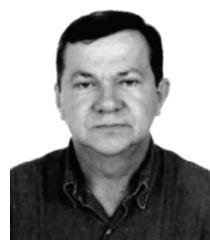

Roberto D. de Medeiros ${ }^{1}$, Wellington F. Araújo² \& Maristélio C. Costa ${ }^{3}$

1 EMBRAPA Roraima, BR 174, Km 08, Distrito Industrial, Boa Vista, RR. E-mail: roberto@cpafrr.embrapa.br. Fone: (095) 626.7125. (Foto)

2 UFRR. E-mail: wfaraujo@osite.com.br

${ }^{3}$ SAAB-RN, Rua José Ovideo Vale, 1914, CEP 59015-410, Natal, RN. Fone: (84) 3206-3232. E-mail: maristelio@rn.gov.br

Protocolo $79-31 / 5 / 2001$ - Aprovado em 13/10/2004

\begin{abstract}
Resumo: Dois experimentos foram conduzidos no Campo Experimental Bom Intento em Boa Vista, RR, de dezembro a março de 1995/96 e 1996/97, com o objetivo de se avaliar os diferentes sistemas de preparo do solo e de irrigação sobre a densidade do solo, e a cultura do feijão caupi cultivado em áreas de várzea. $O$ delineamento experimental foi em blocos casualizados, no esquema de parcelas subdivididas com quatro repetições. $O$ feijão cv. Sempre Verde foi testado sob os sistemas de irrigação por sulcos e aspersão convencional, em dois sistemas de preparo do solo: grade aradora + grade niveladora, grade aradora + arado de aiveca + grade niveladora. Não houve diferenças significativas nos componentes de produção nem na produtividade do feijão caupi irrigado, obtendo-se o rendimento médio de grãos de $1.853 \mathrm{~kg} \mathrm{ha}^{-1}$, porém a densidade do solo aumentou significativamente $(p<0,05)$, quando o seu preparo foi efetuado pela grade aradora + niveladora.
\end{abstract}

Palavras-chave: Vigna unguiculata, aspersão, sulcos

\section{Effect of tillage systems and irrigation methods on cowpea crop on wetland soil in Roraima}

\begin{abstract}
Two experiments were carried out during December, 1995 to March, 1996 and from December, 1996 to March, 1997 at the Experimental Station of Bom Intento, Boa Vista, RR. The objective was to evaluate the effects of different irrigation systems and tillage on soil bulk density and cowpea crop on wetland soils. The experimental design consisted of a split plot in a randomized block design, with four replications. The cowpea cv. Sempre Verde was tested under furrow and sprinkler irrigation in two soil tillage systems, as follows: disc harrow + leveling disc harrow and plough grid + leveller grid + moldboard plough. There were no significant differences among treatments with respect to production components and the crop yield. The mean grain yield was $1,853 \mathrm{~kg} \mathrm{ha}^{-1}$. The soil bulk density after tillage with plough grid + leveller grid was significantly $(p<0.05)$ increased in comparison with the other tillage practices.
\end{abstract}

Key words: Vigna unguiculata, sprinkler, furrow irrigation, soil tillage.

\section{INTRODUÇÃO}

Em Roraima, as áreas de várzea irrigáveis ocupam cerca de 360.000 ha e se estima que 8.000 ha são explorados com a cultura do arroz. O uso dessas várzeas com o monocultivo, aliado a intensa utilização de máquinas, implementos agrícolas e insumos durante três a quatro anos consecutivos, tem causado problemas, como o decréscimo da produtividade, aumentando a infestação de plantas daninhas, resultando na baixa qualidade do produto final, o que tem levado os produtores a abandonarem essas áreas em busca de outras ainda não exploradas, gerando problemas ao meio ambiente (Cordeiro et al., 1996).

Sistemas de preparo do solo, emprego da irrigação e uso da rotação de culturas, estão entre as técnicas de plantio que incrementam o rendimento agrícola.

No preparo de solo convencional, através de aração seguida de gradagem, o espaço poroso do solo pode ser alterado 
provocando, inicialmente, aumento na macroporosidade e diminuição da microporosidade e densidade do solo. Com o cultivo excessivo ou repetido durante anos, há redução na macroporosidade e na infiltração de água, com reflexo no rendimento das culturas (Centurion \& Demattê, 1985). Segundo Bezerra (1978), o preparo do solo com arado de aiveca diminui o impacto negativo causado ao solo em comparação com o método tradicional.

Quanto à irrigação, sua finalidade básica é proporcionar à cultura um suprimento hídrico adequado, possibilitando altos rendimentos e produtos de boa qualidade. Os métodos mais utilizados para culturas anuais são a aspersão e a irrigação por sulco, cada um apresentando, suas vantagens e desvantagens, quanto aos custos de implantação, do manejo da água e de operacionalização. A irrigação também tem de ser bem manejada, já que os solos das várzeas, bastante argilosos, apresentam-se com drenagem deficiente que, associada a alta demanda evaporativa, pode resultar em sérios problemas de salinização (Bernardo, 1995).

A rotação de culturas tem como objetivo principal auxiliar no controle de plantas daninhas e de insetos, na manutenção da matéria orgânica e do nitrogênio do solo. Neste sentido, as leguminosas, por fixarem o nitrogênio do ar, figuram obrigatoriamente num esquema de rotação, para melhorar a fertilidade do solo (Fundação Cargill, 1984).

O feijão caupi apresenta-se como alternativa viável a ser testada em rotação com a cultura do arroz, por sua expressiva importância socioeconômica na região, já que é a principal fonte de proteína vegetal de baixo custo para a alimentação humana. Particularmente e em relação ao feijão irrigado, lâminas de água irregulares favorecem a proliferação de uma incidência maior de doenças na parte aérea, como mofo-branco e antracnose, principalmente nos sistemas de irrigação por aspersão; entretanto, o fator limitante não é o método de irrigação, mas o manejo inadequado da água (Fancelli \& Dourado Neto, 1999).

Estudos realizados por Siqueira (1989) avaliando o efeito de diferentes preparos do solo sobre o feijoeiro cultivado em duas épocas do ano, mostraram maiores rendimentos da cultura conduzida durante o período chuvoso com o solo preparado através do arado de disco. Silva (1995) testando diferentes sistemas de preparo na cultura do feijão em variados ambientes, constatou que, sob condições ideais de umidade do solo, não houve diferenças significativas na produtividade de grãos, porém onde as condições hídricas não foram ideais, o preparo com grade ocasionou menores rendimentos.

Pesquisas desenvolvidas por Aguiar (1989), com o feijão caupi irrigado por aspersão sob diferentes manejos de água e adubação, indicaram maiores rendimentos com uma lâmina de $226 \mathrm{~mm}$ e $181 \mathrm{~kg} \mathrm{ha}^{-1}$ de NPK, enquanto uma lâmina maior (315 $\mathrm{mm}$ ) proporcionou rendimentos menores, devido a redução na porosidade livre de água. Em experimentos de competição de cultivares de feijão sob os métodos de irrigação por sulco e por aspersão, conduzidos por Rochedo et al. (1988) não foram encontradas diferenças significativas na produtividade da cultura, exceto quando comparadas com a testemunha sem irrigação.

O presente trabalho objetivou avaliar diferentes sistemas de preparo do solo e métodos de irrigação sobre a densidade do solo, os componentes de produção e a produtividade de grãos do feijão caupi em áreas de várzea.

\section{MATERIAL E MÉTODOS}

Dois experimentos foram conduzidos nos anos agrícolas 1995/96 e 1996/97, de dezembro/março, em várzea na Estação Experimental Bom Intento, pertencente à EMBRAPA-RR, no município de Boa Vista, Roraima. As coordenadas geográficas locais de referência são $2^{\circ} 49^{\prime} 11$ " $\mathrm{N}$ de latitude, $60^{\circ} 40^{\prime} 24$ " W de longitude e $90 \mathrm{~m}$ de altitude. O clima da região é do tipo Awi, de acordo com a classificação de Köppen, apresentando um período com acentuado déficit hídrico de aproximadamente seis meses no ano, além da ocorrência de veranicos no período chuvoso (Araújo et al., 2001).

O solo é Glei Pouco Húmico Tb álico A moderado, textura argilosa (SUDAM, 1996). As características químicas, físicas e hídricas, na camada de 0 a $20 \mathrm{~cm}$ de profundidade, antes da implantação dos experimentos, são apresentadas na Tabela 1.

No primeiro ensaio, o solo foi corrigido com $1.500 \mathrm{~kg} \mathrm{ha}^{-1} \mathrm{de}$ calcário dolomítico (PRNT 100\%) e $50 \mathrm{~kg}$ de FTE BR12. A adubação de semeadura constou de $450 \mathrm{~kg} \mathrm{ha}^{-1}$ da fórmula $4-28-20+Z n(0,3 \%)$. Em cobertura, foram aplicados $45 \mathrm{~kg} \mathrm{ha}^{-1} \mathrm{de}$ $\mathrm{N}$ aos 25 dias após a emergência, utilizando-se uréia como fonte. No segundo ano de cultivo, foram utilizados $300 \mathrm{~kg} \mathrm{ha}^{-1}$ da fórmula 10-26-26, incorporados aos sulcos de semeadura; já para a cobertura, usou-se a mesma quantidade de $45 \mathrm{~kg} \mathrm{ha}^{-1} \mathrm{de}$ $\mathrm{N}$.

O feijão (Vigna unguiculata (L) Walp) cv Sempre Verde, foi semeado em linhas espaçadas em 1,0 m, com densidade média, após o desbaste, de 4,5 plantas $\mathrm{m}^{-1}$. Os tratos culturais foram intensificados, procurando-se manter a cultura livre de plantas daninhas e fitomoléstias.

O delineamento experimental foi em blocos casualizados, no esquema de parcelas subdivididas, com quatro repetições. As parcelas (sistemas de irrigação) com área de $40 \mathrm{~m}^{2}$ foram separadas por uma distância de $15 \mathrm{~m}$ e subdivididas em duas subparcelas de $20 \mathrm{~m}^{2}$, nas quais se testaram os sistemas de preparo do solo (subparcelas) em área útil considerada de $9 \mathrm{~m}^{2}$ $(3 \times 3 \mathrm{~m})$ composta por três fileiras centrais com $3 \mathrm{~m}$ de comprimento.

Os tratamentos foram os seguintes: $\mathrm{T}_{1}$ - Irrigação por sulco; $\mathrm{T}_{2}$ - Irrigação por aspersão convencional e sistemas de preparo do solo: $\mathrm{T}_{3}$ - grade aradora (duas passadas a $20 \mathrm{~cm}$ de profundidade) + grade niveladora (duas passadas a $10 \mathrm{~cm} \mathrm{de}$ profundidade) e $\mathrm{T}_{4}$ - grade aradora (uma gradagem a $20 \mathrm{~cm}$ de profundidade) + arado de aiveca (uma aração a $30 \mathrm{~cm}$ de

Tabela 1. Características químicas, físicas e hídricas do solo da área experimental, na profundidade de 0 a $20 \mathrm{~cm}$

\begin{tabular}{|c|c|c|c|c|c|c|c|c|c|c|c|c|}
\hline \multirow{2}{*}{$\begin{array}{c}\mathrm{pH} \\
\left(\mathrm{H}_{2} \mathrm{O}\right)\end{array}$} & \multirow{2}{*}{$\begin{array}{c}\mathrm{MO} \\
\left(\mathrm{g} \mathrm{kg}^{-1}\right)\end{array}$} & \multirow{2}{*}{$\begin{array}{c}P \\
\left(\mathrm{mg} \mathrm{dm}^{-3}\right)\end{array}$} & K & $\mathrm{Ca}$ & $\mathrm{Mg}$ & $\mathrm{Al}$ & \multicolumn{3}{|c|}{ Granulometria $\left(\mathrm{g} \mathrm{kg}^{-1}\right)$} & $\mathrm{CC}$ & PMP & \multirow{2}{*}{$\begin{array}{l}\text { D. solo } \\
\left(\mathrm{kg} \mathrm{dm}^{-3}\right)\end{array}$} \\
\hline & & & \multicolumn{4}{|c|}{$\left(\mathrm{cmol}_{\mathrm{c}} \mathrm{dm}^{-3}\right)$} & Areia & Silte & Argila & \multicolumn{2}{|c|}{$(\%)$} & \\
\hline 4,4 & 28,3 & 11,9 & 0,25 & 1,31 & 0,46 & 2,87 & 130 & 260 & 610 & 38 & 23 & 1,2 \\
\hline
\end{tabular}


profundidade) + grade niveladora (duas gradagens a $10 \mathrm{~cm}$ de profundidade).

O sistema de irrigação por aspersão foi constituído por uma linha de aspersores modelo MD20, acoplado a uma haste com $50 \mathrm{~cm}$ de altura e diâmetro de $3 / 4$ ", espaçado $12 \mathrm{~m}$, operando a pressão de serviço de $253 \mathrm{kPa}$, com precipitação média de 10 $\mathrm{mm} \mathrm{h}^{-1}$ e coeficiente de uniformidade de $75 \%$.

O sistema de irrigação por sulco era constituído por um canal principal, do qual se derivava a água para as parcelas, através dos sulcos de irrigação com $10 \mathrm{~m}$ de comprimento e declividade média de $0,1 \%$, espaçados $1 \mathrm{~m}$, com vazão média de $0,5 \mathrm{~L} \mathrm{~s}^{-1}$. Devido ao pequeno comprimento do sulco, considerou-se uma eficiência de irrigação de $50 \%$.

Fez-se o monitoramento da irrigação através de duas baterias de tensiômetro, instaladas a 15 e $40 \mathrm{~cm}$ de profundidade, respectivamente, irrigando-se quando a água atingia, na profundidade de $15 \mathrm{~cm}$, a tensão matricial na faixa entre $50 \mathrm{e}$ $60 \mathrm{kPa}$. Com base na curva característica de umidade do solo, calculou-se a lâmina de irrigação procurando-se elevar a umidade crítica correspondente à capacidade de campo se considerando, também, a profundidade média de $20 \mathrm{~cm}$. Este critério de reposição de água ao solo foi o mesmo para os dois sistemas de irrigação; entretanto, apenas o tempo de irrigação variou conforme a característica de cada sistema.

Todos os preparos de solo foram efetuados no mesmo dia, estando o solo com teor médio de umidade de $15 \%$. Um trator marca Massey Ferguson, modelo MF-296, equipado com diferentes implementos, foi utilizado para efetuar as seguintes operações: gradagem com arado, através de uma grade de disco com controle hidráulico marca Marchesan, modelo GACR; gradagem com niveladora, utilizando-se de uma grade de disco marca Tatu, modelo GNL 32 × 20 e aração efetuada com um arado de aiveca marca Maschietto, modelo A4.

A evapotranspiração potencial ocorrida durante a execução dos experimentos foi estimada a partir do mês de janeiro, através de um tanque classe "A", e as precipitações pluviométricas foram medidas por meio de um pluviômetro instalado na área experimental.

Avaliaram-se a densidade do solo, o número de vagens por metro quadrado, o número de grãos por vagem, a massa de 100 grãos e a produtividade de grãos de feijão.

Amostragens de solos para determinação da densidade foram feitas após a colheita do segundo experimento, na profundidade de 0 a $30 \mathrm{~cm}$, utilizando-se o método do anel volumétrico, de acordo com EMBRAPA (1997) e se retiraram três amostras de solo por subparcela. Obteve-se o número de vagens por meio da contagem de todas as vagens colhidas na área útil, enquanto o número de grãos por vagem o foi através da média de grãos verificada em 10 vagens. Encontrou-se a massa de 100 grãos através da média obtida em 10 subamostras de 100 grãos, e o rendimento foi obtido através da pesagem dos grãos colhidos na área útil, sendo o peso corrigido para $13 \%$ de umidade.

Todas as variáveis foram submetidas à análise de variância, com aplicação do Teste $\mathrm{F}$, e as médias da densidade do solo foram comparadas pelo teste de Duncan a 5\%.

\section{RESULTADOS E DISCUSSÃO}

Em média, nos dois experimentos a evapotranspiração potencial foi de 140,0,121,3 e 135,0 mm, respectivamente, para os meses de janeiro, fevereiro e março. Os dados de precipitação pluviométrica foram de: 24,8, 28,4 e 26,2 mm para os mesmos, respectivamente. O turno de rega foi de três dias, com aplicação de lâminas de $15,0 \mathrm{~mm}$ para ambos os métodos, totalizando $320,0 \mathrm{~mm}$ para todo o ciclo da cultura.

Os valores da densidade do solo são mostrados na Tabela 2 , na qual se verifica que o preparo do solo, utilizando-se a grade aradora + grade niveladora, propiciou maior densidade do solo, diminuindo sua porosidade total e aeração. Resultados semelhantes foram obtidos por Centurion \& Demattê (1985); entretanto, Machado et al. (1981), estudando o comportamento de um Latossolo Vermelho-Escuro cultivado durante quatro anos consecutivos com cultivo convencional, não observaram aumento significativo na densidade do solo.

Tabela 2. Densidade do solo obtida sob diferentes sistemas de irrigação e preparo do solo em várzea

\begin{tabular}{|c|c|}
\hline & do Solo $\left(\mathrm{kg} \mathrm{dm}^{-3}\right)$ \\
\hline \multicolumn{2}{|c|}{ Sistemas de Irrigação } \\
\hline Aspersão & $1,38 \mathrm{a}$ \\
\hline Sulco & $1,29 \mathrm{a}$ \\
\hline \multicolumn{2}{|l|}{$\mathrm{CV}=6,9 \%$} \\
\hline \multicolumn{2}{|c|}{ Preparo do Solo } \\
\hline Grade + arado aiveca + grade & $1,27 \mathrm{a}$ \\
\hline Grade aradora + niveladora & $1,40 \mathrm{~b}$ \\
\hline $\mathrm{CV}=7,7 \%$ & \\
\hline
\end{tabular}

A densidade do solo não foi afetada significativamente pelos sistemas de irrigação nem por sua interação destes com o preparo do solo (Tabela 2). Quanto à irrigação, ambos os métodos atenderam satisfatoriamente à demanda hídrica da cultura, propiciando bons rendimentos, sendo obtido um rendimento médio de $1.853 \mathrm{~kg} \mathrm{ha}^{-1}$ de grãos, bem acima da média obtida sob condições de sequeiro no Estado, que é de $300 \mathrm{~kg}$ ha $^{-1}$ (FECOR,1997).

Em relação aos componentes de produção e à produtividade de grãos não foram afetados significativamente pelos tratamentos testados (Tabela 3). Rochedo et al. (1988) também não encontraram diferenças significativas no rendimento do feijoeiro irrigado por aspersão nem por sulco.

É importante ressaltar que a irrigação por sulco requer equipamentos de menor potência ou, muitas vezes, dispensa sistemas para bombeamento da água, diminuindo os custos das instalações em relação à irrigação por aspersão. Por outro lado, a irrigação por aspersão não exige sistematização do terreno, podendo ser empregada nos diferentes tipos de solo, requerendo menos mão-de-obra e propiciando melhor controle da água de irrigação (Bernardo, 1995). Portanto, essas considerações precisam ser levadas em conta pelo produtor, durante o processo de tomada de decisão. 
Tabela 3. Média dos componentes de produção e rendimento de grãos de caupi, obtidos sob diferentes métodos de irrigação e preparo do solo em várzea

\begin{tabular}{|c|c|c|c|c|}
\hline Tratamentos & $\begin{array}{l}\text { Vagem } \\
\left(\mathrm{n}^{\mathrm{o}} \mathrm{m}^{-2}\right)\end{array}$ & $\begin{array}{c}\text { Grãos } \\
\text { por vagem }\end{array}$ & $\begin{array}{c}\text { Massa de } \\
100 \text { grãos (g) }\end{array}$ & $\begin{array}{l}\text { Rendimento } \\
\left(\mathrm{kg} \mathrm{ha}^{-1}\right)\end{array}$ \\
\hline \multicolumn{5}{|c|}{ Sistemas de Irrigação } \\
\hline Aspersão & 91,87 & 14,72 & 16,16 & $1.904,7$ \\
\hline Sulcos & 86,20 & 13,90 & 15,80 & $1.802,9$ \\
\hline Teste $\mathrm{F}(\mathrm{p}<0,05)$ & $0,17^{\mathrm{ns}}$ & $5,26^{\mathrm{ns}}$ & $0,20^{\mathrm{ns}}$ & $1,67^{\mathrm{ns}}$ \\
\hline CV (\%) & 15,40 & 3,56 & 2,13 & 6,09 \\
\hline \multicolumn{5}{|c|}{ Preparo do solo } \\
\hline $\begin{array}{l}\text { Grade + aiveca } \\
+ \text { niveladora }\end{array}$ & 89,10 & 14,41 & 16,17 & $1.857,0$ \\
\hline $\begin{array}{l}\text { Grade aradora } \\
+ \text { niveladora }\end{array}$ & 88,97 & 14,21 & 15,70 & $1.850,6$ \\
\hline Teste F $(\mathrm{P}<0,05)$ & $0,05^{\mathrm{ns}}$ & $0,67^{\mathrm{ns}}$ & $0,23^{\mathrm{ns}}$ & $0,01^{\mathrm{ns}}$ \\
\hline CV $(\%)$ & 12,46 & 3,40 & 3,90 & 7,01 \\
\hline Média & 89,03 & 14,31 & 15,96 & $1.853,8$ \\
\hline
\end{tabular}

Os resultados evidenciam a baixa exigência da cultura quanto ao preparo do solo (Tabela 3). Resultados semelhantes foram obtidos por outros autores (Zaffaroni et al., 1991; Pimentel \& Chaves, 1993) que também não detectaram efeito significativo no rendimento do feijão caupi cultivado em solo Gley Pouco Húmido sob diferentes manejos do solo; entretanto, Correia et al. (1990) constataram maiores produtividades do feijão quando utilizaram o arado de aiveca. Stone \& Moreira (2000) trabalharam também com feijão em diferentes sistemas de preparo de solo e notaram que o número de grãos por vagem e de vagens por planta foi significativamente afetado pelo sistema de preparo do solo, com melhores resultados para o plantio direto, fato não confirmado por Arf et al. (2004) cujo preparo do solo com arado de aiveca propiciou maior produtividade de grãos em relação ao plantio direto. Os autores comentam que no plantio direto ocorreu um ataque maior de mofo-branco em relação aos tratamentos com revolvimento do solo.

\section{CONCLUSÕES}

1. O preparo do solo através de grade aradora + arado de aiveca + grade niveladora ensejou menor densidade do solo e não afetou os componentes de produção nem o rendimento de grãos de feijão.

2. Os sistemas de irrigação não alteraram significativamente a densidade do solo nem o rendimento de grãos de feijão.

3. A cultura do caupi irrigada apresentou bom rendimento técnico na área de várzea, revelando ser uma boa alternativa podendo, portanto, ser utilizada na rotação com a cultura do arroz.

\section{LITERATURA CITADA}

Aguiar, J.V. Determinação do consumo de água e da função de produção do caupi irrigado no Município de Bragança, Pará. Fortaleza: UFC, 1989. 106p. Dissertação Mestrado
Araújo, W.F.; Andrade Júnior, A.S. de; Medeiros, R.D. de; Sampaio, R.A. Precipitação pluviométrica mensal provável em Boa Vista, Estado de Roraima, Brasil. Revista Brasileira de Engenharia Agrícola e Ambiental, Campina Grande, v.5, n.3, p.563-567, 2001.

Arf, O.; Rodrigues, R.A.F.; Sá, M. E.; Buzetti, S.; Nascimento, V. Manejo do solo, água e nitrogênio no cultivo do feijão. Pesquisa Agropecuária Brasileira, Brasília, v.39, n.2, p.131138, 2004.

Bernardo, S. Manual de irrigação. 6. ed. Viçosa: Imprensa Universitária, $1995.657 \mathrm{p}$.

Bezerra, J.E.S. Influência de sistemas de manejo do solo sobre algumas propriedades físicas e químicas de um Podzólico Vermelho-Amarelo câmbico distrófico, fase terraço, e sobre a produção de milho (Zea mays L.). Viçosa: UFV, 1978. 61p. Dissertação Mestrado

Centurion, J.F.; Demattê, J.L.I. Efeitos de sistemas de preparo nas propriedades físicas de um solo sob cerrado cultivado com soja. Revista Brasileira de Ciência do Solo, Campinas, v.9, n.3, p.263-266, 1985.

Cordeiro, A.C.C.; Medeiros, R.D. de; Gianluppi, D.; Ó, W.C.R. do; Pereira, R.L.; Freitas, J.Q. Pesquisa em várzea. Boa Vista: EMBRAPA, CPAF-RR, 2p. 1996. EMBRAPA Informa, 2

Correia, J.R.; Freitas de, P.L.; Gomes, M.A.N. Efeito dos sistemas de preparo do solo na cultura do feijão sob pivô central . In: Reunião sobre feijão irrigado (GO,DF,MG,ES,SP,RJ), 1, 1990, Goiânia. Anais... Goiânia: EMBRAPA CNPAF, 1990. p.152156.

EMBRAPA. Empresa Brasileira de Pesquisa Agropecuária. Centro Nacional de Pesquisa de Solos (Rio de Janeiro, RJ). Manual de métodos de análise de solo. 2.ed. Rio de Janeiro: EMBRAPA - CNPS, 1997.212p. Documentos 1

Fancelli, A.L.; Dourado Neto, D. Feijão irrigado: Estratégia básica de manejo. Piracicaba: Publique. 1999.194p.

FECOR - Federação do Comércio. Roraima 96: Economia e mercado. Boa Vista: FECOR, 1997. 114p.

Fundação Cargill. Adubação orgânica, adubação verde e rotação de culturas no Estado de São Paulo. 2. ed. Campinas: Fundação Cargill. 1984.138p.

Machado, J.A.; Paula Souza, D.M. de; Brum, A.C.R. de. Efeito de anos de cultivo convencional em propriedades físicas do solo. Revista Brasileira de Ciência do Solo, Campinas, v.5, n.1, p.187-189, 1981.

Pimentel, G.B.M.; Chaves, R.S. Produtividade do caupi sob diferentes sistemas de manejo de um solo de várzea do médio Amazonas Paraense. Revista Brasileira de Ciência do Solo, Campinas, v.17, n.1, p.135-138, 1993.

Rochedo, P.R.C.; Shuch, L.O.B.; Zonta, E.P.; Vernetti Jr., F.J. Competição de cultivares de feijoeiro (Phaseolus vulgaris L.) sob dois métodos de irrigação. In: Congresso Nacional de Irrigação e Drenagem, 8, 1998. Florianópolis. Anais... Florianópolis: Associação Brasileira de Irrigação e Drenagem, 1988, p.11-21. 
Silva, V.A. da. Efeitos de métodos de preparo do solo e níveis de fertilizante NPK sobre o feijão da "seca" (Phaseolus vulgaris $L$.) em seqüência à cultura do milho (Zea mays L.). Lavras: UFLA, 1995. 66p. Dissertação Mestrado

Siqueira, N.de S. Efeitos de métodos de preparo do solo sobre a cultura do feijão (Phaseolus vulgaris L.) e sobre algumas propriedades físicas e químicas do solo. Viçosa: UFV, 1989. 106p. Dissertação Mestrado

Stone,L.F.; Moreira, J.A.A. Efeitos de sistemas de preparo do solo no uso da água e na produtividade do feijoeiro. Pesquisa Agropecuária Brasileira, Brasília, v.35, n.4, p.835-841, 2000.
SUDAM - Superintendência do Desenvolvimento da Amazônia. Caracterização dos solos, avaliação da aptidão agrícola das terras e indicativo de culturas para as várzeas do Cerrado do Estado de Roraima. Belém: SUDAM/OEA/EMBRAPA/ CPATU. 1996. v.1. 128p. Relatório Final

Zaffaroni, E.; Barros, H.H. de; Nobrega, J.A.M.; Lacerda, J.T. de; Souza Junior, V.E. de. Efeito de métodos de preparo do solo na produtividade e outras características agronômicas de milho e feijão no Nordeste do Brasil. Revista Brasileira de Ciência do Solo, Campinas, v.15, n.1, p.187-189, 1991. 